\title{
Spontaneous Mediumship Experiences: A Neglected Aftereffect of Near-Death Experiences
}

\author{
Janice Miner Holden, Ed.D. \\ University of North Texas \\ Ryan D. Foster, Ph.D. \\ Marymount University \\ Lee Kinsey, M.S. \\ University of North Texas
}

\begin{abstract}
In talking with near-death experiencers (NDErs), we had encountered cases of what we called spontaneous mediumship experiences (SMEs) in which the NDEr experienced an uninvited visit by a deceased person who asked the NDEr to convey a message to another living person. We were unable to find reference to this phenomenon in the existing NDE literature. In this article, we present a brief case study and results of an exploratory quantitative study of SMEs among NDErs. We created a 38-item online survey and recruited adult participants primarily through the International Association for Near-Death Studies' approximately 45 local U.S. groups. The 89 participants were predominantly female White non-Latina/o. Whereas $15 \%$ of participants reported at least one SME prior to their first or only NDE, 56\% reported at least one following it. Participants reporting deeper NDEs were significantly more likely to report at least one post-NDE SME, with a medium effect. Number of reported post-NDE SMEs ranged from 1 to over 20. Of those who reported degree of distress related to their SMEs, only 4\% indicated very or extremely distress-
\end{abstract}

\footnotetext{
Janice Miner Holden, Ed.D., LPC-S, LMFT, NCC, ACMHP, is professor in the Counseling Program and chair of the Department of Counseling and Higher Education at the University of North Texas in Denton. Her primary research focus is counseling and consciousness implications of transpersonal experiences, primarily near-death experiences. Ryan D. Foster, Ph.D., LPC, NCC, CHST, is assistant professor of counseling at Marymount University in Arlington, VA. Lee Kinsey, M.S., LPC, is a doctoral candidate in the Counseling Program at the University of North Texas in Denton. This paper was presented at the American Center for the Integration of Spiritually Transformative Experiences (ACISTE) 3rd Annual Conference on Therapeutic Issues of Spiritually Transformative Experiences, Dallas, TX, November 6-8, 2014. Correspondence regarding this article should be sent to Dr. Holden at e-mail: jan.holden@ unt.edu.
} 
ful. Of participants who responded, $28 \%$ reported having sought help with their SMEs, 62\% reported they had found at least one helpful coping strategy, and the most frequent source of helpful coping strategies was reportedly personal experience. We discuss implications of these findings for healthcare providers working with NDErs and for consciousness researchers. Based on our results, further research, both quantitative and qualitative, seems warranted regarding this apparently heretofore uninvestigated NDE aftereffect.

KEY WORDS: near-death experience, aftereffects, mediumship, spontaneous mediumship experience, after-death communication

Since 1975 when Raymond Moody's (1975/2001) book Life After Life first familiarized the public and most professionals with near-death experiences (NDEs), researchers have conducted over 65 studies involving over 2,500 near-death experiencers (NDErs) on four continents (Holden, Greyson, \& James, 2009). As a result, much is now known about the circumstances, contents, and aftereffects of NDEs. Of everyone who survives a close brush with death, about one in five reports a typically real or hyper-real experience of one's consciousness continuing to function, typically apart from the physical body, perceiving the material world - either close to or distant from the body-and/ or perceiving and interacting with transmaterial environments and beings, such as deceased loved ones and spiritual entities (Zingrone \& Alvarado, 2009). The experience is typically predominantly emotionally pleasurable but is sometimes predominantly distressing (Bush, 2009), and it can range from simple, with few features, to complex, with numerous detailed features. In general, the more complex the NDE, the more the NDEr will subsequently evidence physical, psychological, spiritual, and social changes-often profound transformation (Noyes, Fenwick, Holden, \& Christian, 2009). Even changes that seem to indicate spiritual development, such as less materialism and greater compassion and concern for others, can be distressing and disruptive-sometimes to the point of psychological and/or physical dysfunction, a phenomenon sometimes termed spiritual emergency (Grof \& Grof, 1989; Holden, VanPelt, \& Warren, 1999).

As much as is known about NDE aftereffects, more remains to be understood. An apparently less-addressed aftereffect is what we have termed spontaneous mediumship experiences (SMEs). SMEs are a subset of after-death communication (ADC). In the following paragraphs, we discuss SMEs in the larger context of the existing ADC literature. 
In ADC, a living person senses the presence of a discarnate (deceased person) who may or may not overtly communicate a message (StreitHorn, 2011). In a recent study, Jenny Streit-Horn (2011) conducted a systematic review of all published research on spontaneous ADC: 35 studies between 1894 and 2006 involving over 50,000 research participants in 24 countries. Her study yielded the most empirically-based conclusions available to date regarding the phenomenon. Regarding prevalence, she found that at least one in three people report ADC some time in their lives. Both bereaved and non-bereaved people report ADC, but more bereaved do: an incidence of at least three out of four within a year of the loss of the loved one. People of both sexes report ADC, but more women do. Regarding other demographics, people report $\mathrm{ADC}$ approximately equally, with some possible but not definite exceptions, such as more frequent reports in cultures that affirm the phenomenon. ADC occurs in all states of consciousness, with possibly the most common being sleep ADC-not "dream ADC" as often termed in the literature, because people reporting ADC (ADCrs) tend to say that these experiences have a subjectively different, more "real" quality by comparison with dreams. ADC also occurs in all states of health, from completely healthy to being on one's deathbed-the latter sometimes termed "deathbed visions."

Though Streit-Horn (2011) found no researchers who had directly assessed the mental health of ADCrs, she noted that many researchers spontaneously commented on the apparently predominant mental health of their participants. Modalities of ADC included all of the senses-visual, auditory, tactile, olfactory, kinesthetic - as well as a more nondescript sense of the discarnate's presence, as well as external modalities such as symbolic-synchronistic songs, butterflies, flowers-and electronic devices such as telephone-with visual and sense of presence being possibly the most frequently reported modalities. In spontaneous ADC, if the discarnate conveys a message, it is for the ADCr, who virtually always feels benefitted by what, for them, is knowledge that the discarnate still exists in a state of wellbeing and that the discarnate still loves and is aware of the ADCr. When distress occurs related to an ADC, it is almost always the result of the ADCr's lack of information or misinformation about ADCs themselves, such as that such experiences are unheard of or that having such an experience indicates mental illness (Streit-Horn, 2011).

A major qualitative study of ADC in Sydney, Australia (Knight, 2011) yielded results in keeping with Streit-Horn's (2011). In recent years, mental health professionals have developed techniques to fa- 
cilitate ADC, and research on the effects is beginning to be published (Botkin \& Hannah, 2013; Hannah, Botkin, Marrone, \& Streit-Horn (2013).

Mediumship is a subphenomenon of ADC in which, instead of the ADCr directly perceiving the discarnate, a third person acts as a medium of communication between the discarnate and the living person (sitter). Most often, a sitter seeks out a medium, someone purportedly skilled in communication with discarnates, to communicate with a particular discarnate, often someone whose death the sitter is grieving. Thus, unlike in either spontaneous or facilitated ADC in which the discarnate is virtually always known to the ADCr, in mediumship the discarnate is almost always unknown to the medium; thus, in $\mathrm{ADC}$, any message is for the ADCr, whereas in mediumship, the message is not for the medium but for the sitter. Well-designed research has revealed that at least some mediums consistently produce specific information that sitters judge to be highly accurate (Rock, Beischel, Boccuzzi, \& Biuso, 2014).

Whereas in ADC spontaneous experiences constitute the majority and facilitated experiences the minority, in mediumship intentional experiences, in which the discarnate is invited to communicate, constitute the majority and spontaneous experiences, in which the discarnate appears uninvited to a medium with a message for another living person, are the minority. For example, in Bill Guggenheim and Judy Guggenheim's (1995) study of ADC, they reported four cases of SME (pp. 282-285) out of an estimated 300 accounts of spontaneous ADC; in all cases, the mediums were adults. Louis LaGrand (1997) provided three cases of "third party contacts"-what we are calling SMEs-from among an estimated 70 cases of spontaneous ADC; although the mediums in two of the three cases were adults, LaGrand observed that children might serve disproportionately as the medium (pp. 127-130). More recently, Kenneth Ring (2008) reported in detail a case in which a veteran paramedic with no history of NDE or ADC experienced spontaneous mediumship of a deceased patient whom she had helped transfer from his home to the hospital where he died a few days later. And most recently, in Knight's (2011) qualitative study of ADC in Sydney, Australia, she found that two of her 21 participant/co-investigators reported that discarnates had used other embodied individuals to convey messages to the participants; the mediums were a child in one case and an adult in the other.

Another factor that differentiates traditional mediumship from spontaneous SMEs is that a traditional medium typically knows the 
sitter, whereas a spontaneous medium may not know the living person for whom the message is intended; even if the person is known, that person typically did not seek a message from the discarnate. These circumstances surrounding spontaneous mediumship can present challenges for the spontaneous medium. I (Holden) had such an experience during a session of Induced After-Death Communication (Holden, 2012), so I can attest to the unique challenges of such experiences. Whereas the cases reported in the literature virtually always are a one-time occurrence for the SMErs who presumably had no history of NDE, many NDErs with whom we have spoken marked their

Table 1 Comparison of Various After-Death Communication-Related Modalities: Summary Observations from Existing Literature*

\begin{tabular}{|c|c|c|c|c|c|}
\hline \multirow[b]{2}{*}{ Feature } & \multicolumn{5}{|c|}{ ADC-related modality } \\
\hline & $\begin{array}{l}\text { Spontane- } \\
\text { ous ADC }\end{array}$ & $\begin{array}{c}\text { Facilitated } \\
\text { ADC }\end{array}$ & $\begin{array}{l}\text { Traditional } \\
\text { medium- } \\
\text { ship }\end{array}$ & $\begin{array}{l}\text { Spontane- } \\
\text { ous medium- } \\
\text { ship: } \\
\text { non-NDEr } \\
\text { medium }\end{array}$ & $\begin{array}{l}\text { Spontane- } \\
\text { ous medium- } \\
\text { ship: NDEr } \\
\text { medium }\end{array}$ \\
\hline $\begin{array}{l}\text { Intentionality } \\
\text { of contact with } \\
\text { discarnate }\end{array}$ & $\begin{array}{l}\text { Usually un- } \\
\text { planned and } \\
\text { unexpected }\end{array}$ & $\begin{array}{l}\text { Planned and } \\
\text { expected }\end{array}$ & $\begin{array}{l}\text { Planned and } \\
\text { expected }\end{array}$ & $\begin{array}{l}\text { Unplanned } \\
\text { and un- } \\
\text { expected }\end{array}$ & $\begin{array}{l}\text { Unplanned } \\
\text { and un- } \\
\text { expected }\end{array}$ \\
\hline $\begin{array}{l}\text { Person in contact } \\
\text { with discarnate }\end{array}$ & $\begin{array}{l}\text { Experiencer } \\
\text { (direct) }\end{array}$ & $\begin{array}{l}\text { Experiencer } \\
\text { (direct), } \\
\text { facilitated by } \\
\text { therapist }\end{array}$ & Medium & Medium & Medium \\
\hline $\begin{array}{l}\text { Relationship of } \\
\text { contact person to } \\
\text { discarnate }\end{array}$ & $\begin{array}{l}\text { Usually } \\
\text { known/close, } \\
\text { sometimes } \\
\text { known/ } \\
\text { acquaintance }\end{array}$ & $\begin{array}{l}\text { Almost al- } \\
\text { ways known/ } \\
\text { close }\end{array}$ & $\begin{array}{l}\text { Almost } \\
\text { always } \\
\text { unknown }\end{array}$ & $\begin{array}{l}\text { Usually } \\
\text { known/close } \\
\text { or known/ } \\
\text { acquain- } \\
\text { tance, rarely } \\
\text { unknown* }\end{array}$ & $\begin{array}{l}\text { Ranging from } \\
\text { known/close } \\
\text { to unknown* }\end{array}$ \\
\hline $\begin{array}{l}\text { Intended recipient } \\
\text { of message from } \\
\text { discarnate }\end{array}$ & Experiencer & Experiencer & $\begin{array}{l}\text { Third person } \\
\text { (“sitter"); } \\
\text { usually } \\
\text { known to } \\
\text { medium }\end{array}$ & $\begin{array}{l}\text { Third person; } \\
\text { known or } \\
\text { unknown to } \\
\text { medium* }\end{array}$ & $\begin{array}{l}\text { Third person; } \\
\text { known or } \\
\text { unknown to } \\
\text { medium* }\end{array}$ \\
\hline $\begin{array}{l}\text { Occurrences of } \\
\text { contacts with } \\
\text { discarnates }\end{array}$ & $\begin{array}{l}\text { Usually } \\
\text { single; some- } \\
\text { times few }\end{array}$ & $\begin{array}{l}\text { Almost al- } \\
\text { ways single }\end{array}$ & Multiple & $\begin{array}{l}\text { Usually } \\
\text { single; some- } \\
\text { times few or } \\
\text { multiple* }\end{array}$ & $\begin{array}{l}\text { Ranging } \\
\text { from single to } \\
\text { multiple* }\end{array}$ \\
\hline
\end{tabular}

\footnotetext{
* Observations in need of research to confirm or to clarify specifics.
} 
NDEs as the onset point of multiple subsequent SMEs. A comparison of features of the various ADC-related phenomena appears in Table 1.

One final feature of SMEs deserves mention. These experiences may provide a unique source of veridical - verifiable-information relevant to the question of the survival of consciousness after death. In the one Internet-published case we know of involving a veridical SME by an NDEr, she reported the following:

My brother-in-law died in 2000. He did not believe in an afterlife. I was on the phone with my sister who lived in Walnut Creek California.

All at once I only could see yellow, like someone put a yellow sheet of paper in front of my eyes. Then it was gone and in my den it was filled with bubbles, thousands of bubbles. This kept happening: the color yellow, then gone; thousands of bubbles, then gone. Then I had a voice in my head saying, "Tell her, tell her, tell her." It became so loud I couldn't even hear my sister any more.

I then said, "Marsha, I have to tell you something, it makes no sense, I am not crazy, but I have to tell you YELLOW BUBBLES." She couldn't believe it. She was happy, so happy. She then told me one night her husband Bob and her watched a movie called Houdini. Bob was making a comment of being no afterlife, Marsha told him she would think of a secret word known only to each and whoever went first if there was an afterlife to somehow get the secret word to the one left here. To my surprise that was the secret words: Yellow Bubbles. She picked them because it made no sense, nobody would ever just blurt out those words unless one of them were telling them to. (Romona B, n.d.; some punctuation added for clarity)

Some NDErs with whom we have spoken reportedly found their SMEs distressing, perhaps especially when they were "plagued" with numerous ongoing SMEs. Despite the occurrence and unique challenges of these experiences, our review of the professional NDE literature resulted in no refereed journal articles on the topic and no reference to SMEs in several recent NDE summary texts, including one for which I (Holden) was lead editor (Atwater, 2007; Holden, Greyson, \& James, 2009; Kason, 2008). The phenomenon appears not to have been addressed in the literature, but because it occurs, can be a source of distress, and holds potential relevance to consciousness research, we believe it should be.

\section{Case Study}

To introduce the phenomenon and unique challenges of SMEs, we present a brief case study. The NDEr, Janie, has reviewed and confirmed the accuracy of the following material. 
In 2008, Janie was a young adult. Her NDE occurred during physical unconsciousness from an acute life-threatening illness; it contained both material and transmaterial features. A few days later, she experienced her first "visitation" from a discarnate:

I was in bed, about to fall asleep, when I 'felt' someone come in the room. It felt like a female and I thought it was my mom. When I opened my eyes to look around for her, no one was there. I thought that my imagination was running wild. This same woman followed me around here and there for 4 years. ...

Since that first experience, Janie has had numerous visitations from other discarnates, most often during the hours of 2:00 to 4:00 a.m. She continued:

I would say that about 5 out of every 10 visitations I get include a message. At that point, the fact that I've received a message almost becomes more distressing than the visitation itself, because I wonder what I'm supposed to do with the message.

Janie provided two recent examples. One involved a friend, Rob, who had died the previous year:

I was out with a group of people and could feel Rob there in the room with us. Standing next to me was one of [Rob's] dear friends that [Rob had] worked with (someone who I've only met once before). Rob wanted me to give [this friend] a message. Without hesitation, I leaned over and told him that Rob was there with us and I gave him the message. [The friend] loved it. He was shocked, but he loved it. He knew it was from Rob and not from me. In that case, it was the right thing to do and I felt that without question in my heart when I did it.

However, the majority of Janie's SMEs are not so straightforward and easy to handle:

One that's causing me difficulties right now is [a man] who passed 4 years ago. I never met him, but we have several mutual friends. He wants me to help his wife and he's a musician and he also wants to channel music through me. He can be pushy and draining.

Janie was so distracted by these experiences that she undertook a mission to informally research the matter. Like us, she found no mention of this phenomenon in the near-death literature. In talking with other NDErs, she

found that NDErs are so humbled by this gift and have such a high feeling of moral obligation about what the right thing/wrong thing is to do with the messages, that we don't fully develop it and it causes stress. We could surely exploit it and make some money from it, but 
it just doesn't feel right so we sit with it in private. For me, there's also tension in developing it further because it feels like developing a psychic gift is possibly a distraction from spirituality. It's an inner tension.

Janie also has sought out professional mediums for advice. She has found that mediums who, themselves, have not had NDEs tended to become defensive, as if she represented professional competition. However, from those willing to help, she has found useful information and strategies for regulating and dealing with her SMEs.

Themes that Janie expressed-finding strategies to regulate SMEs; struggling with the morality of whether, when, and how to share SME messages with the living people for whom they were intended; wrestling with the tension between psychic and spiritual development; coping with "holding" messages undelivered; and others-are reminiscent of themes I (Holden) have found in talking with other NDErs who have had SMEs. Yet many questions remain regarding this phenomenon and those who experience it: What is the retrospectively reported incidence of SMEs both prior to and following an NDE? What is the retrospectively reported frequency of SMEs prior to and following NDE? What is the relationship between retrospectively reported incidence of SME both prior to and following an NDE and depth of the NDE? How distressing do SMErs report retrospectively that their SMEs were? Among SMErs who report retrospectively that they sought help, how many report retrospectively that they found at least one helpful strategy? Among SMErs who report retrospectively that they found at least one helpful strategy, what do they report retrospectively was the source[s] of that help?

To begin to answer these questions, we undertook a mixed methods exploratory study of SMEs among NDErs. In this article, we describe our method and preliminary results focused primarily on the quantitative data; in the future, we plan to publish a second article focusing primarily on the qualitative data and a third and final article in which we present two in-depth case studies that most richly convey the phenomenological quality of SMEs and their sequelae.

\section{Method}

\section{Instruments}

We developed a 38-item survey; upon obtaining University of North Texas and Marymount University Institutional Review Board ap- 
proval to conduct this study, we posted it on the Internet via Qualtrics software. The survey began with Section 1 (25 items) to assess participant demographics (7 items), to assess presence and complexity of an NDE via the Near-Death Experience Scale (NDE Scale; 16 items; Greyson, 1983; Lange, Greyson, \& Houran, 2005), and to assess presence or absence of the experience of having been "visited at least once by a deceased person who communicated a message they wanted you to convey to another living person" both before and after their NDE (2 items). The NDE Scale produces a score ranging from 0 to 32, with a score of 7 or above indicating an NDE and a higher score indicating a more complex-more elaborate, intense, deeper-NDE. The Scale also measures presence and complexity of four NDE content domains: cognitive, affective, paranormal, and transcendental. Since the Scale's strong psychometric properties were first established (Greyson, 1983), they have been reconfirmed through numerous studies (Zingrone \& Alvarado, 2009) and a Rasch scaling analysis (Lange et al., 2004). Using the current data, we found the total score of the NDE Scale to be reliable (Henson, 2001) with Cronbach's alpha of .83, whereas subscale reliabilities ranged from reliable to questionable: .60 for the cognitive domain, .81 for the affective domain, .59 for the paranormal domain, and .71 for the transcendental domain. Based on these results, we used only total score in subsequent analyses.

Section 2 (13 items) began with a definition of SME: "the experience of being visited by a deceased person who communicated a message they wanted you to convey to another living person." We then asked about the number of post-NDE SMEs and, if participants had indicated SMEs both before and after their NDEs, about a comparison of the quality of the two experiences. Participants then identified the SME they considered least distressing and indicated what made this experience least distressing and the degree of distress of both the experience and its aftermath; they then answered the same questions regarding their most distressing SME. Next we asked participants how distressing they have found their SMEs overall, what they considered the most challenging aspect of their SMEs, how their response to their SMEs has changed over time, whether they sought help to manage or cope with their SMEs, and whether they have found any strategies helpful in managing or coping. If they answered that last question affirmatively, we asked them to describe up to three such strategies and the source of each, and we concluded with "Anything else about your SMEs?" 


\section{Participants}

We recruited participants for the study primarily through the International Association for Near-Death Studies' approximately 45 local groups throughout the US. The group coordinator agreed to send our invitation to the group leaders along with a request that they distribute the invitation to their group members via their email lists and at in-person meetings. We also recruited through various online means-NDE-related websites, forums, and groups, including the Near-Death Experience Research Foundation-asking identified leaders or administrators either to display an invitation on their website or to email it to their membership. In the advertisements or in the email invitations, we defined SMEs and asked individuals to participate if they were at least 18 years old, were fluent in English, and either had or believed they may have had an NDE-whether or not they had experienced SMEs. To maximize breadth of respondent demographics, we imposed no further restrictions on participation. In all cases, potential participants were directed to our online Qualtrics survey.

During nine months of online administration of our survey, 146 people accessed the Informed Consent form. Of these, four did not endorse it, 28 endorsed it but made no further responses, 15 endorsed it and completed the demographics but no further items, and $10 \mathrm{com}$ pleted all items but scored below 7 on the NDE Scale. The remaining 89 completed all items and scored 7 or higher on the NDE Scale; these comprised our participants.

Participant demographic data appear in Table 2. Although characteristics such as age, education, year of NDE, and circumstances of NDE were diverse among the sample, sex and ethnicity were fairly homogeneous: Most participants were female and White, non-Latina/o.

\section{Results}

We used SPSS 22.0 and G*Power (Faul, Erdfelder, Lang, \& Buchner, 2007) software to analyze the data. Following are descriptions of incidence and frequency of SMEs and data surrounding coping with NDEs.

\section{Incidence and Frequency of SMEs}

Results regarding our participants' retrospectively reported incidence of SMEs before and after their first or only NDEs appear in Table 3. 
Table 2 Participant Demographics $(N=89)$

\begin{tabular}{|c|c|c|c|}
\hline & & $n$ & $\%$ \\
\hline \multirow[t]{2}{*}{ Sex } & Female & 58 & $65.2 \%$ \\
\hline & Male & 31 & $34.8 \%$ \\
\hline \multirow[t]{5}{*}{ Ethnicity } & Asian & 1 & $1.1 \%$ \\
\hline & Latina/o & 2 & $2.2 \%$ \\
\hline & White, non-Latina/o & 76 & $85.4 \%$ \\
\hline & Bi-racial & 2 & $2.2 \%$ \\
\hline & Other & 8 & $9.0 \%$ \\
\hline Age & $\begin{array}{l}\text { Range: } 20-73 \text { years } \\
\text { Mean: } 53.28 \text { years }\end{array}$ & & \\
\hline \multirow[t]{5}{*}{ Education } & Some high school & 2 & $2.2 \%$ \\
\hline & High school diploma/equivalent & 9 & $10.1 \%$ \\
\hline & Some college & 31 & $34.8 \%$ \\
\hline & Bachelor's degree & 17 & $19.1 \%$ \\
\hline & Graduate degree & 30 & $33.7 \%$ \\
\hline \multirow[t]{4}{*}{ Circumstances of NDE } & Illness or health crisis & 42 & $47.2 \%$ \\
\hline & Injury & 29 & $32.6 \%$ \\
\hline & Suicide attempt & 4 & $4.5 \%$ \\
\hline & Other & 14 & $15.7 \%$ \\
\hline Year of NDE & $\begin{array}{l}\leq 1970 \\
1971-1980 \\
1981-1990 \\
1991-1999 \\
2000-2009 \\
\geq 2010\end{array}$ & $\begin{array}{l}17 \\
14 \\
18 \\
12 \\
16 \\
12\end{array}$ & $\begin{array}{l}19.1 \% \\
15.7 \% \\
20.2 \% \\
13.5 \% \\
18.0 \% \\
13.5 \%\end{array}$ \\
\hline
\end{tabular}

Table 3 Incidence of Retrospectively Reported SMEs Before and After First or Only NDE and NDE Scale Total Scores

NDE Scale total score

\begin{tabular}{lrrrc} 
Category of NDEr re: SMEs & \multicolumn{1}{c}{$n / N$} & \multicolumn{1}{c}{$\%$} & \multicolumn{1}{c}{$M$} & \multicolumn{1}{c}{$S D$} \\
\hline No SME before or after NDE & 39 & $43.8 \%$ & 15.85 & 5.06 \\
No SME before NDE; at least one after & 37 & $41.6 \%$ & 19.43 & 5.23 \\
At least one SME before NDE; none after & 3 & $3.4 \%$ & 23.33 & 3.06 \\
At least one SME before and after NDE & 10 & $11.2 \%$ & 17.30 & 8.78 \\
Total & 89 & $100.0 \%$ & 17.75 & 5.85 \\
\hline
\end{tabular}


Only a minority of our participants (14.6\%) reported at least one SME prior to their first or only NDE. Of the majority (84.4\%) who reported no pre-NDE SMEs, approximately half (51.3\%) reported no post-NDE SMEs, and the other half (48.7\%) reported they experienced at least one SME for the first time following their NDE.

To analyze the data surrounding occurrence of SMEs, we computed mean total scores for the NDE Scale (Greyson, 1983; Lange, Greyson, \& Houran, 2005) for each of the four categories of participants; see Table 3. Initially, we were interested in exploring how retrospectively reported occurrence of SME both prior to and following NDE related to depth of NDE. Because the very uneven distribution of participants in the four categories violated assumptions underlying ANOVA, we were unable to answer the research questions as originally stated. However, because we were particularly interested in the majority of our participants who reported no pre-NDE SMEs, and the numbers in the two categories (didn't or did have post-NDE SME) were nearly equal, we focused further analysis on those two groups.

Following confirmation of all requisite assumptions, including normality and Levene's test for equality of variances, an independent samples $t$ test revealed that among our participants with no pre-NDE SMEs, those who reported at least one post-NDE SME $(n=37)$ had significantly higher NDE Scale scores than those who did not $(n=39)$, $t(74)=-3.039, p=.003$, two-tailed. In the absence of norms for effect size in NDE research, we used Jacob Cohen's (1988) cautious specifications to assess strength of effect for eta squared: .01 $\approx$ small; .06 $\approx$ medium; . $14 \approx$ large. The magnitude of differences in the means (mean difference $=-3.586,95 \%$ CI: -5.937 to -1.235$)$ was medium $\left(\eta^{2}=.11\right)$. Thus, among NDErs who reportedly had not had an SME prior to their first or only NDE, those with deeper NDEs were more likely to report at least one SME following their NDEs.

To be cautious in our interpretation of the data given the small sample size (Stevens, 1996), we ran a post-hoc power analysis using G*Power (Faul, Erdfelder, Lang, \& Buchner, 2007) to determine if our sample size was sufficient. Cohen (1988) suggested a minimum power of .80 in order to assess adequacy of sample size. Post-hoc power analysis showed that an independent samples $t$ test with a sample size of 76 and an effect size of $\eta^{2}=.11$ yielded a power of 0.84 . Thus, the sample size was sufficient, and there were actual differences between the groups.

In addition to whether participants reported at least one SME before and after their first or only NDE, we wondered, among those 
Table 4 Frequency of Retrospectively Reported SMEs

\begin{tabular}{lcccc}
\hline $\begin{array}{l}\text { Number of retrospectively } \\
\text { reported SMEs }\end{array}$ & \multicolumn{2}{c}{ Before first/only NDE } & \multicolumn{2}{c}{ After first/only NDE } \\
& $n^{1}$ & $\%$ & $n^{2}$ & $\%$ \\
\hline 1 & 3 & $30 \%$ & 8 & $17.4 \%$ \\
$2-5$ & 2 & $20 \%$ & 16 & $34.8 \%$ \\
$6-10$ & 1 & $10 \%$ & 5 & $10.9 \%$ \\
$11-20$ & 0 & $0 \%$ & 2 & $4.4 \%$ \\
$>20$ & 4 & $40 \%$ & 15 & $32.6 \%$ \\
\hline
\end{tabular}

${ }^{1}$ Of 13 participants who indicated at least one $S M E$ before their first/only NDE, 3 did not respond to the frequency question.

${ }^{2}$ Of 47 participants who indicated at least one SME after their first/only NDE, 1 did not respond to the frequency question.

who reported at least one, how many SMEs they had experienced. Results regarding frequency of retrospectively reported SMEs appear in Table 4.

\section{Coping with SMEs}

We asked participants to complete items related to how distressing they found their SMEs to have been and in what ways they have coped with their SMEs. Because most SMEs reportedly occurred after a first or only NDE, we focused on respondents who indicated post-NDE SMEs $(n=47)$. Regarding overall distress related to their SMEs, $28 \%$ of participants did not answer, and the remainder indicated not at all distressful (30\%), slightly distressful (17\%), moderately distressful (21\%), very distressful (2\%), and extremely distressful (2\%).

In terms of coping with SMEs, $45 \%$ of participants who indicated at least one post-NDE SME reported that they never sought help to manage or cope with their SMEs, $28 \%$ indicated that they did seek help, and the remaining $27 \%$ did not answer the question. Regarding specific coping strategies, $62 \%$ of participants indicated that they had found at least one helpful strategy, $11 \%$ indicated that they had not, and the remaining $27 \%$ did not answer the question. Out of those respondents who indicated that they found at least one helpful strategy, 29 respondents answered an item that asked them from where they learned these strategies. The helpful sources of strategies they indicated were from personal experience (65.5\%); from another NDEr, through direct communication with them, their speech, or their pub- 
lication (6.9\%); from a medium who was not an NDEr, through direct communication with them, their speech, or their publication (3.4\%); from a mental health professional who was not an NDEr (such as a counselor, psychologist, clinical social worker), through direct communication with them, their speech, or their publication (0\%); from some other source (13.8\%); and all of the above (10.3\%). Participants indicated types of helpful strategies through free responses, so results require qualitative analysis and will be reported in a future publication.

\section{Discussion}

To the extent that our participants' responses represent those of NDErs in general, our results indicate some possible actions for healthcare providers - medical, mental health, social, and spiritual - to take when working with NDErs in the immediate or later aftermath of NDEs. For the purpose of discussion, we will couch our comments in this context of recommendations to healthcare providers (HPs).

Recommendations for HPs working with NDErs (Foster, James, \& Holden, 2009) include, in the immediate NDE aftermath, preparing NDErs for possible aftereffects and how to cope with them, and, in the longer aftermath, identifying what aftereffects the NDEr has experienced and the degree of coping. Knowing that intensity of NDEs has been related to intensity of aftereffects and, in particular, to greater likelihood that an NDEr will experience one or more SMEs, in the immediate aftermath of a possible NDE an HP might administer the NDE Scale to determine the presence and depth of the NDE. By way of preparing the NDEr for possible aftereffects, the HP would do well to assess a patient's/client's interest in and readiness to discuss what research has revealed about aftereffects. Upon finding the NDEr ready and interested, and in the context of a discussion about various possible aftereffects, the HP might introduce the topic of SMEs; state that preliminary research indicates that prior to an NDE, only about 1 in 10 NDErs has had an SME; and inquire whether the NDEr patient/client is in the $90 \%$ who has not or the $10 \%$ who has had a preNDE SME. Whatever the NDEr's response, the healthcare provider might continue by reporting that the same research indicates that after their NDEs, about half reported no SMEs, and the other half reported at least one-so most of the latter half are first-time SMErs. Of these, in the years following their NDEs, over half reported a total of five or fewer SMEs, and less than a third reported 20 or more, so most SMErs have few SMEs-but some have several. 
The HP might continue by offering that to the uninitiated, SMEs might sound frightening, but the great majority of participants in that research reported little or no distress related to their SMEs, and among those who sought help regarding their SMEs, most found it through their own experience or through talking with, reading the writings of, or hearing talks by NDErs - or even mediums. At this point the HP might reference the NDEr's NDE Scale score and convey that if the score is relatively higher-say, the high teens or higherthe NDEr may be more likely to experience at least one SME, or if relatively lower-say, the low teens or lower, less likely—but that these are only tendencies and that some high scorers don't have SMEs and some low scorers do. The HP could conclude by letting the NDEr know that if they are in the small minority of people who experiences distress with this or any aftereffect, they could seek support from organizations such as the International Association for Near-Death Studies (www.iands.org) and/or the American Center for the Integration of Spiritually Transformative Experiences (www.aciste.org) - and, of course, provide the NDEr with the HP's business card for any subsequent needs the NDEr might have.

In the longer-term aftermath of an NDE, an HP might take much the same tack, except rather than preparing the NDEr for possible aftereffects, instead inquiring into what aftereffects the NDEr has experienced and the extent to which the NDEr is coping with them. In our clinical experience, NDErs are more likely to self-identify psychospiritual changes such as loss of fear of death, decrease in materialism, and increase in caring and compassion-and less likely to "connect" certain aftereffects to their NDEs-such as electromagnetic effects whereby electronic devices malfunction in the NDEr's presence or NDErs feel increased sensitivity to electromagnetic energy-until they come upon this information from external sources and, upon reflection, realize the information applies to them. Our finding that SMEs have gone virtually unaddressed in the professional literature, but that over half of our research participants, when asked, reported post-NDE SMEs, indicates that this aftereffect might belong in the latter category: less likely for NDErs to report spontaneously but more likely for them to recognize when asked directly. Thus, HPs may need to be prepared to initiate the specific topic of SMEs.

HPs need to be prepared for the possibility that the prospect of SMEs might be unsettling or disturbing for some NDErs. In her recent extensive qualitative study of ADCrs, Knight (2009) found that for ADCrs whose worldviews already included belief in ADC, their 
worldviews were confirmed by their ADCs, whereas for those whose worldviews did not include such belief, they altered their worldviews to accommodate their ADCs that they had experienced as quite real and always eventually psychospiritually constructive. SMErs might manifest the same dynamics, and particularly in the latter type of case, HPs may be able to facilitate the accommodation process. Of course, in order to do so, HPs are probably best prepared to help SMErs if they themselves have, or have found, an integrated place for SMEs in their own worldviews.

Considering that to our knowledge the SME phenomenon has not been addressed directly in the professional literature, it is not surprising that our participants who sought help with their SMEs reported that HPs were not a substantial source of help to them. The information herein, and particularly our upcoming report of qualitative analysis of the exact nature of helpful strategies, may contribute substantially to HPs' preparation to assist NDE SME clients in need of help to cope with SMEs.

Although we have focused our discussion on implications of our findings for healthcare professionals, another area of implication is consciousness studies, in particular the hypotheses that the brain is a receiver/transmitter, rather than producer, of consciousness and that consciousness survives bodily death. An important source of data pertaining to these hypotheses is veridical information from phenomena such as NDEs, ADC, and past-life memories. When people perceive information, especially idiosyncratic information as in the "yellow bubbles" case cited above, that they could not have otherwise known, under controlled conditions, and the accuracy of that information is subsequently verified, that information provides data in support of the aforementioned hypotheses. If, as our results suggest, large numbers of NDErs experience SMEs, their experiences might be researched for what they have to offer regarding these hypotheses, and they might serve as participants in controlled studies of veridical SMEs.

\section{Limitations and Conclusion}

We acknowledge that this is an exploratory study, and such studies involve a number of limitations. The first and perhaps most obvious limitation was our use of an Internet survey format only, which likely limited our sample to respondents who had at least some comfort with the use of technology and Internet-based surveys. NDErs who either did not have access to the Internet or who were uncomfortable with 
Internet-based surveys or technology in general did not respond to this survey, limiting its generalizability. Another limitation related to sampling was due to our sampling approach: We sampled only NDErs who were involved in NDE groups and/or who were seeking NDE information online. Finally, due to substantial attrition during the survey-roughly three quarters of participants answered the entire questionnaire-we have a limited view of coping strategies; this topic remains for future researchers to elucidate.

Even considering these limitations, it can be said with confidence that at least some NDErs who had not experienced SMEs prior to their NDEs experience them afterwards, and some NDErs describe their SMEs as distressing and seek help to cope with them. The specific findings from our sample remain to be confirmed or modified through further research, which, on the basis of our findings, seems very warranted. In particular, we suggest that future researchers investigate this apparent aftereffect through not only extended and refined quantitative means but also through qualitative means in order to assess the lived experiences of NDErs who report SMEs. Another tantalizing question for future researchers is whether results might differ among NDErs outside the US, especially those from cultures possibly more open to and accepting of transpersonal experiences such as ADC and mediumship.

In the meantime, as indicated above, HPs who work with NDErs probably serve these patients/clients best by inquiring into and psychoeducating about NDE aftereffects in general and SMEs in particular. At the very least, HPs can provide reassurance that such experiences are not uncommon in the aftermath of an NDE and can join clients who have felt distressed around their SMEs to inquire into the distress, possibly help to reduce or eliminate it, and accompany clients as they seek to discover mechanisms to reduce and/or cope with these sometimes challenging experiences. Meanwhile, consciousness researchers may consider how accounts of SMEs - and SMErs themselves-might provide additional data regarding hypotheses about the relationship between consciousness and the brain.

\section{References}

Atwater, P. M. H. (2007). The big book of near-death experiences: The ultimate guide to what happens when we die. Charlottesville, VA: Hampton Roads.

Botkin, A. L., \& Hannah, M. T. (2013). Brief report: Psychotherapeutic outcoes reported by therapists trained in Induced After-Death Communication. Journal of Near-Death Studies, 13(4), 221-224. 
Bush, N. E. (2009). Distressing Western near-death experiences: Finding a way through the abyss. In J. M. Holden, B. Greyson, \& D. James (Eds.), The handbook of near-death experiences: Thirty years of investigation (pp. 63-86). Santa Barbara, CA: Praeger/ABC-CLIO.

Cohen, J. (1988). Statistical power analysis for the behavioral sciences (2nd ed.). Hillsdale, NJ: Erlbaum.

Faul, F., Erdfelder, E., Lang, A. G., \& Buchner, A. (2007). G*Power 3: A flexible statistical power analysis program for the social, behavioral, and biomedical sciences. Behavior Research Methods, 39, 175-191.

Foster, R., James, D., \& Holden, J. M. (2009). Practical applications of research on near-death experiences. In J. M. Holden, B., Greyson, \& D. James (Eds.), The handbook of near-death experiences: Thirty years of investigation (pp. 235-258). Santa Barbara, CA: Praeger/ABC-CLIO.

Grof, S., \& Grof, C. (Eds.). (1989). Spiritual emergency: When personal transformation becomes a crisis. Los Angeles, CA: Jeremy P. Tarcher.

Hannah, M. T., Botkin, A. L., Marrone, J. G., \& Streit-Horn, J. (2013). Brief report: Induced After-Death Communication: An update. Journal of Near-Death Studies, 13(4), 213-220.

Henson, R. K. (2001). Understanding internal consistency reliability estimates: A conceptual primer on coefficient alpha. Measurement and Evaluation in Counseling and Development, 34, 177-189.

Holden, J. M. (2012). Hourglass of love. In J. Canfield, M. V. Hansen, \& A. Newmark (Eds.), Chicken soup for the soul: Messages from heaven (pp. 55-57). Cos Cob, CT: Chicken Soup for the Soul.

Holden, J. M., Greyson, B., \& James, D. (2009). The field of near-death studies: Past, present, and future. In J. M. Holden, B. Greyson, \& D. James (Eds.), The handbook of near-death experiences: Thirty years of investigation (pp. 1-16). Santa Barbara, CA: Praeger/ABC-CLIO.

Holden, J. M., VanPelt, P. T., \& Warren, S. (1999). Spiritual emergency: An introduction and case example. Counseling and Values, 43, 163-177.

Kason, Y. (2008). Farther shores: Exploring how near-death, kundalini, and mystical experiences can transform ordinary lives. Bloomington, IN: iUniverse.

Knight, M. (2011). Ways of being: The alchemy of bereavement and communiqué (doctoral dissertation). Sydney, Australia: University of Sydney.

Moody, R. (2001). Life after life: The investigation of a phenomenon-survival of bodily death. San Francisco, CA: Harper. (Original work published 1975)

Noyes, R., Fenwick, P., Holden, J. M., \& Christian, R. (2009). Aftereffects of pleasurable Western adult near-death experiences. In J. M. Holden, B. Greyson, \& D. James (Eds.), The handbook of near-death experiences: Thirty years of investigation (pp. 41-62). Santa Barbara, CA: Praeger/ABC-CLIO.

Ring, K. (2008). The death and posthumous life of Tom Sawyer: A case study of apparent after-death communication. Journal of Near-Death Studies, 17(2), 111-133.

Rock, A. J., Beischel, J., Boccuzzi, M., \& Biuso, M. (2014). Discarnate readings by claimant mediums: Assessing phenomenology and accuracy under beyond double-blind conditions. Journal of Parapsychology, 78(2), 183-194.

Romona B. (n.d.). Romona B's NDE. Retrieved from http://www.nderf.org/ NDERF/NDE_Experiences/romona_b\%27s_nde.htm 
Stevens, J. (1996). Applied multivariate statistics for the social sciences (3rd ed.). Mahwah, NJ: Lawrence Erlbaum.

Streit-Horn, J. A systematic review of research on after-death communication $(A D C)$ (Doctoral dissertation). Available from ProQuest Dissertations and Theses database. (AAT No. 3506993)

Zingrone, N. L., \& Alvarado, C. S. Pleasurable Western adult near-death experiences: Features, circumstances, and incidence. In J. M. Holden, B. Greyson, $\&$ D. James (Eds.), The handbook of near-death experiences: Thirty years of investigation (pp. 17-40). Santa Barbara, CA: Praeger/ABC-CLIO. 